\title{
Photosynthetic Bradyrhizobium Sp. Strain ORS285 Synthesizes 2-O-Methylfucosylated Lipochitooligosaccharides for nod Gene-Dependent Interaction with Aeschynomene Plants
}

\author{
Adeline Renier, ${ }^{1}$ Fabienne Maillet, ${ }^{2}$ Joel Fardoux, ${ }^{1}$ Véréna Poinsot, ${ }^{3}$ Eric Giraud, ${ }^{1}$ and Nico Nouwen ${ }^{1}$ \\ ${ }^{1}$ Laboratoire des Symbioses Tropicales et Méditerranéennes, UMR113 IRD, Laboratoire des Symbioses Tropicales et \\ Méditerranéennes, UMR IRD/SupAgro/INRA/UM2/CIRAD, F-34398 Montpellier, France; ${ }^{2}$ Laboratoire des Interactions \\ plantes/microorganismes LIPM, UMR441/2594 INRA/CNRS 441/2594, 24 chemin de Borde Rouge, 31326 Castanet- \\ Tolosan, France; ${ }^{3}$ Laboratoire des Interactions Moléculaires et Réactivité Chimique et Photochimique, UMR 5623 \\ CNRS/Université Paul Sabatier, 118 Route de Narbonne, F-31062 Toulouse, France
}

Submitted 3 May 2011. Accepted 15 August 2011.

Bradyrhizobium sp. strain ORS285 is a photosynthetic bacterium that forms nitrogen-fixing nodules on the roots and stems of tropical aquatic legumes of the Aeschynomene genus. The symbiotic interaction of Bradyrhizobium sp. strain ORS285 with certain Aeschynomene spp. depends on the presence of nodulation (nod) genes whereas the interaction with other species is nod gene independent. To study the nod gene-dependent molecular dialogue between Bradyrhizobium sp. strain ORS285 and Aeschynomene spp., we used a $\operatorname{nodB}$-lac $Z$ reporter strain to monitor the nod gene expression with various flavonoids. The flavanones liquiritigenin and naringenin were found to be the strongest inducers of nod gene expression. Chemical analysis of the culture supernatant of cells grown in the presence of naringenin showed that the major Nod factor produced by Bradyrhizobium sp. strain ORS285 is a modified chitin pentasaccharide molecule with a terminal $\mathrm{N}-\mathrm{C}_{18: 1}$-glucosamine and with a 2-O-methyl fucose linked to $\mathrm{C}-6$ of the reducing glucosamine. In this respect, the Bradyrhizobium sp. strain ORS285 Nod factor is the same as the major Nod factor produced by the nonphotosynthetic Bradyrhizobium japonicum USDA110 that nodulates the roots of soybean. This suggests a classic nod gene-dependent molecular dialogue between Bradyrhizobium sp. strain ORS285 and certain Aeschynomene spp. This is supported by the fact that $B$. japonicum USDA110 is able to form $\mathbf{N}_{2}$-fixing nodules on both the roots and stems of Aeschynomene afraspera.

Rhizobia have the ability to establish a symbiotic relationship with leguminous plants. In this association, the bacteria induce the plant to develop a new organ, the nodule, in which the symbiont resides and fixes atmospheric nitrogen. This complex interorganismal relationship is mediated by signal mole-

Corresponding author: N. Nouwen; E-mail: nico.nouwen@ird.fr

* The $\boldsymbol{e}$-Xtra logo stands for "electronic extra" and indicates that one supplementary figure is published online and Figure 5 appears in color online.

This article is in the public domain and not copyrightable. It may be freely reprinted with customary crediting of the source. The American Phytopathological Society, 2011. cules produced by both bacteria and plants (Spaink 1992). Leguminous plants synthesize and exude a diverse array of phenolic compounds such as flavonoids into the rhizosphere. These compounds serve as chemoatractants for rhizobia, influence bacterial growth, and selectively induce the expression of bacterial nodulation (nod) genes, leading to the biosynthesis of the bacterial signal molecules, the Nod factors (NF) (CaetanoAnolles et al. 1988; Dharmatilake and Bauer 1992). NF are composed of three to five 1-4 $\beta$-linked $N$-acetyl glucasamine units (GlcNac) with the $N$-acetyl group of the terminal nonreducing sugar replaced by an acyl chain with 16 or 18 carbons and with varying degrees of saturation. Various modifications at both reducing and nonreducing termini of the chitin backbone are possible, such as methylation, acetylation, carbamoylation, fycosylation, or sulfation (D'Haeze and Holsters 2002; Perret et al. 2000). The structure of the fatty acyl chain, the number of GlcNac residues, and the presence of extra substituents determine the host specificity of the bacterium (Denarie et al. 1996). Thus, it is not surprising that broad host range symbionts such as Rhizobium sp. strain NGR234, Rhizobium fredii, $R$. tropici, and certain Bradyrhizobium spp. produce a range of NF (Bec-Ferte et al. 1996; Carlson et al. 1993; Poupot et al. 1993; Price et al. 1992).

Photosynthetic Bradyrhizobium spp. establish a symbiotic interaction with tropical aquatic legumes of the Aeschynomene genus (Giraud and Fleischman 2004). In addition to being photosynthetic, these bacteria and the interaction with Aeschynomene have other atypical characteristics compared with the classical and well-studied rhizobia-legume interaction. First, photosynthetic Bradyrhizobium spp. are able to fix nitrogen in the free living state (Alazard 1990). Second, in addition to nodulating roots, photosynthetic Bradyrhizobium spp. are also able to nodulate the stems of Aeschynomene plants (Alazard 1985). Third, the infection process of the plant does not involve root hair curling but bacteria enter the plant via epidermal fissures ("cracks") generated by the emergence of lateral or adventive roots (Sprent 2008). Fourth, certain photosynthetic Bradyrhizobium spp. (ORS278 and BTAi1) lack the genes that encode the enzymes that synthesize the core structure of NF (nodABC) (Giraud et al. 2007). This indicates that some photosynthetic Bradyrhizobium spp. likely use a novel mechanism, independent of the long-time considered universal NF to interact with their legume hosts. 
Photosynthetic Bradyrhizobium sp. strain ORS285 has a broad host range and interacts with many plants in the Aeschynomene genus (Molouba et al. 1999). In contrast to the recently (completely) sequenced photosynthetic Bradyrhizobium sp. strains ORS278 and BTAi1 (Giraud et al. 2007), strain ORS285 contains the nodABC genes (Chaintreuil et al. 2001). However, whereas a deletion of the nodBC genes in Bradyrhizobium sp. strain ORS285 results in the inhibition of nodulation of certain plants in the Aeschynomene genus, the mutant was still able to interact with a subgroup of plants that are nodulated by photosynthetic Bradyrhizobium spp. that do not contain nodABC genes (Giraud et al. 2007). This indicates that Bradyrhizobium sp. strain ORS285 interacts with certain Aeschynomene plants in a nod gene-dependent manner whereas, with others, it is using (or can use) a nod gene-independent mechanism.

In many aspects, the interaction between photosynthetic Bradyrhizobium spp. and Aeschynomene spp. is different from the classical rhizobia-legume interaction; therefore, the aim of this study was to determine which signal molecules are involved in the nod gene-dependent molecular dialogue between photosynthetic Bradyrhizobium sp. strain ORS285 and Aeschynomene spp. (i.e., the flavonoids that induce the expression of the nodABC operon and the determination of the NF structures produced by the bacterium).

\section{RESULTS}

The flavanones liquiritigenin and naringenin are strong inducers of $\operatorname{nod} \mathrm{B}$ expression.

The photosynthetic Bradyrhizobium sp. strain ORS285 contains an operon containing the common nod genes (nodABC) (Chaintreuil et al. 2001) that are involved in the synthesis of the core structure of NF in other rhizobia. To determine which flavonoids induce the expression of genes in the nodABC operon, we used a Bradyrhizobium sp. strain ORS285 reporter strain which contained a nodB-lac Z transcriptional fusion on the chromosome. Growth of this re- porter strain in the presence of flavonoids of different functional classes (Fig. 1) showed that the flavanones liquiritigenin and naringenin result in the highest induction of $\beta$ galactosidase activity (Table 1). Because both activities were not significantly different, C5 hydroxylation (as found in naringenin) seems not to be very important for inducing capacity. C3' hydroxylation of flavanones leads to a twofold reduction in $\beta$-galactosidase activity, whereas flavanones with a methoxy or glucoside at the $\mathrm{C} 7$ position (naringenin-7-Oglucoside, sakuranetin, and sakuranin) are inactive. Flavones are approximately twofold less active in induction of $\operatorname{nodB}$ lac Z expression compared with flavanones. As with flavanones, attachment of a glucoside at the $\mathrm{C} 7$ position (apigenin7-O-glucoside and luteolin-7-O-glucoside) results in a com-<smiles>O=C1C[C@H](c2ccccc2)Oc2ccccc21</smiles>

Flavanone<smiles>O=c1c(O)c(-c2ccccc2)oc2ccccc12</smiles>

Flavonol<smiles>O=c1cc(-c2ccccc2)oc2ccccc12</smiles>

Flavone<smiles>O=c1c(-c2ccccc2)coc2ccccc12</smiles>

Isoflavone
Fig. 1. Basic chemical structures of a flavanone, flavone, flavonol, and isoflavone.

Table 1. Induction of the Bradyrhizobium sp. strain ORS285 nodB-lacZ fusion by flavonoids

\begin{tabular}{|c|c|c|c|c|c|c|}
\hline \multirow[b]{2}{*}{ Putative inducer } & \multicolumn{5}{|c|}{ Hydroxylation pattern } & \multirow[b]{2}{*}{ Miller units } \\
\hline & 3 & 5 & 7 & $\mathbf{3}^{\prime}$ & $4^{\prime}$ & \\
\hline \multicolumn{7}{|l|}{ Flavanones } \\
\hline Liquiritigenin & $\ldots$ & & $\mathrm{OH}$ & $\ldots$ & $\mathrm{OH}$ & $3,676 \pm 486$ \\
\hline Naringenin & $\ldots$ & $\mathrm{OH}$ & $\mathrm{OH}$ & $\ldots$ & $\mathrm{OH}$ & $4,265 \pm 274$ \\
\hline Naringenin-7-O-glucoside & $\ldots$ & $\mathrm{OH}$ & Glu & $\ldots$ & $\mathrm{OH}$ & $945 \pm 67$ \\
\hline Eriodictyol & $\ldots$ & $\mathrm{OH}$ & $\mathrm{OH}$ & $\mathrm{OH}$ & $\mathrm{OH}$ & $1,709 \pm 205$ \\
\hline Hesperetin & $\ldots$ & $\mathrm{OH}$ & $\mathrm{OH}$ & $\mathrm{OH}$ & Metx & $1,108 \pm 124$ \\
\hline Sakuranetin & $\ldots$ & $\mathrm{OH}$ & Metx & $\ldots$ & $\mathrm{OH}$ & $799 \pm 100$ \\
\hline Sakuranin & $\ldots$ & Glu & Metx & $\ldots$ & $\mathrm{OH}$ & $801 \pm 66$ \\
\hline \multicolumn{7}{|l|}{ Flavones } \\
\hline 7,4'-dihydroxyflavone & $\ldots$ & & $\mathrm{OH}$ & $\ldots$ & $\mathrm{OH}$ & $2,758 \pm 251$ \\
\hline Apigenin & $\ldots$ & $\mathrm{OH}$ & $\mathrm{OH}$ & $\ldots$ & $\mathrm{OH}$ & $2,290 \pm 270$ \\
\hline Apigenin-7-O-glucoside & $\ldots$ & $\mathrm{OH}$ & Glu & $\ldots$ & $\mathrm{OH}$ & $869 \pm 142$ \\
\hline Acacetin & $\ldots$ & $\mathrm{OH}$ & $\mathrm{OH}$ & $\ldots$ & Metx & $1,093 \pm 111$ \\
\hline Luteolin & $\ldots$ & $\mathrm{OH}$ & $\mathrm{OH}$ & $\mathrm{OH}$ & $\mathrm{OH}$ & $2,227 \pm 293$ \\
\hline Luteolin-7- $O$-glucoside & $\ldots$ & $\mathrm{OH}$ & Glu & $\mathrm{OH}$ & $\mathrm{OH}$ & $839 \pm 57$ \\
\hline \multicolumn{7}{|l|}{ Flavonols } \\
\hline Kaempferol & $\mathrm{OH}$ & $\mathrm{OH}$ & $\mathrm{OH}$ & $\ldots$ & $\mathrm{OH}$ & $1,483 \pm 204$ \\
\hline Kaempferol-3- $O$-glucoside & Glu & $\mathrm{OH}$ & $\mathrm{OH}$ & $\ldots$ & $\mathrm{OH}$ & $744 \pm 85$ \\
\hline Kaempferide & Glu & $\mathrm{OH}$ & $\mathrm{OH}$ & $\ldots$ & Metx & $816 \pm 35$ \\
\hline Quercetin & $\mathrm{OH}$ & $\mathrm{OH}$ & $\mathrm{OH}$ & $\mathrm{OH}$ & $\mathrm{OH}$ & $833 \pm 95$ \\
\hline Isoquercitrin & Glu & $\mathrm{OH}$ & $\mathrm{OH}$ & $\mathrm{OH}$ & $\mathrm{OH}$ & $826 \pm 33$ \\
\hline \multicolumn{7}{|l|}{ Isoflavones } \\
\hline Daidzein & $\ldots$ & $\ldots$ & $\mathrm{OH}$ & $\ldots$ & $\mathrm{OH}$ & $837 \pm 51$ \\
\hline Daidzin & $\ldots$ & $\ldots$ & Glu & $\ldots$ & $\mathrm{OH}$ & $770 \pm 63$ \\
\hline Formononetin & $\ldots$ & $\ldots$ & $\mathrm{OH}$ & $\ldots$ & Metx & $810 \pm 36$ \\
\hline Genistein & $\ldots$ & $\mathrm{OH}$ & $\mathrm{OH}$ & $\ldots$ & $\mathrm{OH}$ & $904 \pm 109$ \\
\hline Control & $\ldots$ & $\ldots$ & $\ldots$ & $\ldots$ & $\ldots$ & $805 \pm 34$ \\
\hline
\end{tabular}


plete inhibition of inducing capacity. Except for kaempferol, all tested flavonols were not able to induce the expression of nodB-lacZ in Bradyrhizobium sp. strain ORS285.

The isoflavones differ from flavones and flavanones in that the $\mathrm{B}$ ring is attached to $\mathrm{C} 3$ instead of $\mathrm{C} 2$. Because all tested isoflavones (daidzein, daidzin, formononetin, and genistein) are unable to induce expression of nodB-lac $\mathrm{Z}$, it can be concluded that the attachment of the B-ring to $\mathrm{C} 2$ as found in flavanones and flavones is crucial for the induction of genes in the nodABC operon of Bradyrhizobium sp. strain ORS285.

\section{The major NF of Bradyrhizobium sp. strain ORS285 is a pentameric $\mathrm{LCO}$ \\ with a 2-O-methylfucose at the reducing end.}

Naringenin was the most active inducer of nodB-lac $\mathrm{Z}$ expression; therefore, this flavonoid was used to obtain maximum nod gene expression and to isolate synthesized NF from the culture supernatant of Bradyrhizobium sp. strain ORS285. HPLC analysis of the butanol extract of uninduced (- naringenin) and induced (+ naringenin) cells showed one major peak that was present in the induced culture but not in the uninduced culture (Fig. 2). Fractions corresponding to this peak in the HPLC profile were collected, pooled, and analyzed by electrospray ionization (ESI)-MS. The positive ion spectrum of compounds in the peak fraction shows that it consists of a mixture of at least four molecules (Fig. 3A; $\mathrm{M}_{1}$ to $\mathrm{M}_{4}$ ). $[\mathrm{M}+\mathrm{Na}]^{+}$ions at $\mathrm{m} / \mathrm{z} 1235.7$ and 1438.8 are compatible with $O$-methyl-fucosylated chitooligomers bearing an $\mathrm{N}$-octadecanoyl substituent. The difference in 203.1 atomic mass units $(\mathrm{amu})$ between $[\mathrm{M}+\mathrm{Na}]^{+}$ions at $\mathrm{m} / \mathrm{z}$ 1235.7 and 1438.8 indicates that the smallest molecule lacks one $\mathrm{N}$-actetylglucosaminosyl residue (203.1 amu) compared with the heaviest one and can be assigned as Nod-IV(C18:1,MeFuc) and Nod-V(C18:1,MeFuc) respectively. The mass difference of $43 \mathrm{amu}$ between $[\mathrm{M}+\mathrm{Na}]^{+}$ions at $\mathrm{m} / \mathrm{z} 1438.8$ and 1481.8 and between 1235.7 and 1278.7 suggest that the two chito-tetra and -pentamers contains an additional carbamoyl group and likely corresponds to Nod-IV(Cb, C18:1, MeFuc) and Nod-V(Cb,

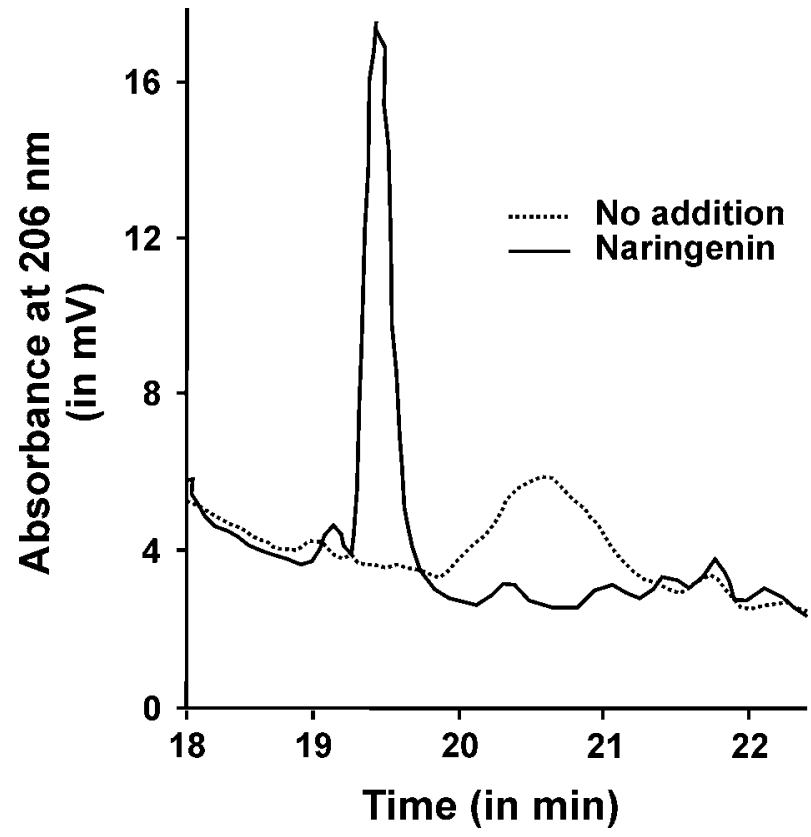

Fig. 2. Elution profile of reverse-phase high-performance liquid chromatography purification of nodulation factors from Bradyrhizobium sp. strain ORS285. The culture supernatant of Bradyrhizobium sp. strain ORS285 cells grown in the presence and absence of naringenin was extracted with $n$-butanol, whereafter the concentrated extract was separated using a C18 reversephase column. Only the relevant part of the chromatogram is shown.
C18:1, MeFuc), respectively. Closer inspection of different spectra of the peak fraction showed that it also contained a very small fraction of $\mathrm{Nod}-\mathrm{V}(\mathrm{C} 16: 0$, MeFuc) (data not shown). Based on the ESI-MS experiments, it can be concluded that Bradyrhizobium sp. strain ORS285 synthesizes at least five different LCO, of which Nod-V(C18:1, MeFuc) is the most abundant one (69\% of the total) when the bacterium is grown in the presence of naringenin (Table 2).

To confirm the structure of the most abundant LCO in the peak fraction, an additional MS/MS experiment was performed (Fig. 3B). With the collision energy set at $30 \mathrm{~V}$, a classical B fragmentation pattern was observed with the major LCO. This fragmentation is due to disruption of the osidic junction between the glucosamine subunits and produces a regular profile with a mass difference of 203.1 amu between each ion corresponding to GlcNac subunits (221.1 amu for the unmodified reducing end). Fragmentation of the molecular ion $[\mathrm{M}+\mathrm{H}]^{+}$of the most abundant LCO produced a neutral loss of $381 \mathrm{amu}$ directly from the molecular species, indicating that the reducing end is modified $(381=221+160)$. This mass of $160 \mathrm{amu}$ corresponds to a methyl fucose group. To our knowledge, only 2-O-methyl-fucose borne by the 6-O of the reducing end has been published as NF modification. The other losses were equivalents of $203.1 \mathrm{amu}$ and the profile ended with a $\mathrm{B}_{1}$ ion at $\mathrm{m} / \mathrm{z} 426$, indicating that the nonreducing end is substituted by a C18:1 acyl. Based on the MS/MS experiment, it can be concluded that the major LCO synthesized by Bradyrhizobium sp. strain ORS285 is Nod-V(C18:1, MeFuc) (Fig. 3C).

\section{Bradyrhizobium sp. strain ORS285 genes encoding enzymes and regulators involved in NF synthesis.}

The synthesis of NF involves many different enzymes whose expression involves a complex regulation mechanism. To analyze whether the synthesized LCO correspond with the nod genes present in the genome and how the expression of these genes might be regulated, we searched published and unpublished DNA sequences of Bradyrhizobium sp. strain ORS285 for known genes involved in NF synthesis, secretion, and regulation. In total, we identified 10 putative genes involved in NF synthesis (nodABCSUZ, noeI, and nolL) and secretion (nod $\mathrm{IJ})$ and 3 putative genes encoding proteins that regulate nod gene expression (nod D1, nod D2, and nolA) (Table 3$)$. The 13 genes, in total, are scattered over six different contigs in the genomic draft of Bradyrhizobium sp. strain ORS285. The largest contig $(8 \mathrm{~kb})$ contains the nodABCSUIJ genes that exhibit a perfect microsyntheny in B. japonicum USDA110 (Supplementary Fig. S1). Comparison of genes involved in the regulation and synthesis of NF between these two strains showed

Table 2. Nodulation factors synthesized by Bradyrhizobium sp. strain ORS $285^{\mathrm{a}}$

\begin{tabular}{lccc}
\hline Structure & $\begin{array}{c}\text { Molecular } \\
\text { weight }\end{array}$ & ESI-MS & $\begin{array}{c}\text { Percentage } \\
(\%)\end{array}$ \\
\hline V, C18:1, MeFuc & 1,416 & $M_{1}$ & 69 \\
V, C18:1 & 1,256 & $\mathrm{M}_{2}$ & 12 \\
V, C18:1, MeFuc, Cb & 1,459 & $\mathrm{M}_{3}$ & 9 \\
IV, C18:1, MeFuc & 1,213 & $\mathrm{M}_{4}$ & 9 \\
V, C16:0, MeFuc & 1,390 & $\ldots$ & 1 \\
\hline
\end{tabular}

${ }^{a}$ Based on the electrospray ionization mass spectrometry (ESI-MS) and tandem MS (MS/MS) spectra, we could identify five different lipochitooligosaccarides (LCO) that are present in the isolated peak fraction from the reverse phase column. The molecular weight and the indication used in the ESI-MS spectrum are given. In the case of carbamoylation $(\mathrm{Cb})$, the location of the carbamoyl group is on the $\mathrm{C} 6$ atom of the terminal Noctadecanoyl-glucosamine residue. The percentage of the different LCO in the peak fraction is based on the different ions found for the corresponding molecule in the ESI-MS spectrum. 
that Bradyrhizobium sp. strain ORS285 does not contain the two-component regulatory system NodV/NodW and also lacks the carbamoyltransferase NolO. In contrast, Bradyrhizobium sp. strain ORS285 possesses a nolL gene that encodes for an acetyl transferase and which is absent in the B. japonicum USDA110 genome. Taken together, in the available DNA sequences of Bradyrhizobium sp. strain ORS285, we could iden- tify all known genes that encode for enzymes that are responsible for the different modifications as found in the synthesized LCO. Moreover, the regulation of nod gene expression involves, as in all other rhizobia, the "classical" regulator NodD, but is likely more complex than a simple induction by flavonoids because a putative gene encoding the cell-density-dependent regulator NolA is also found.

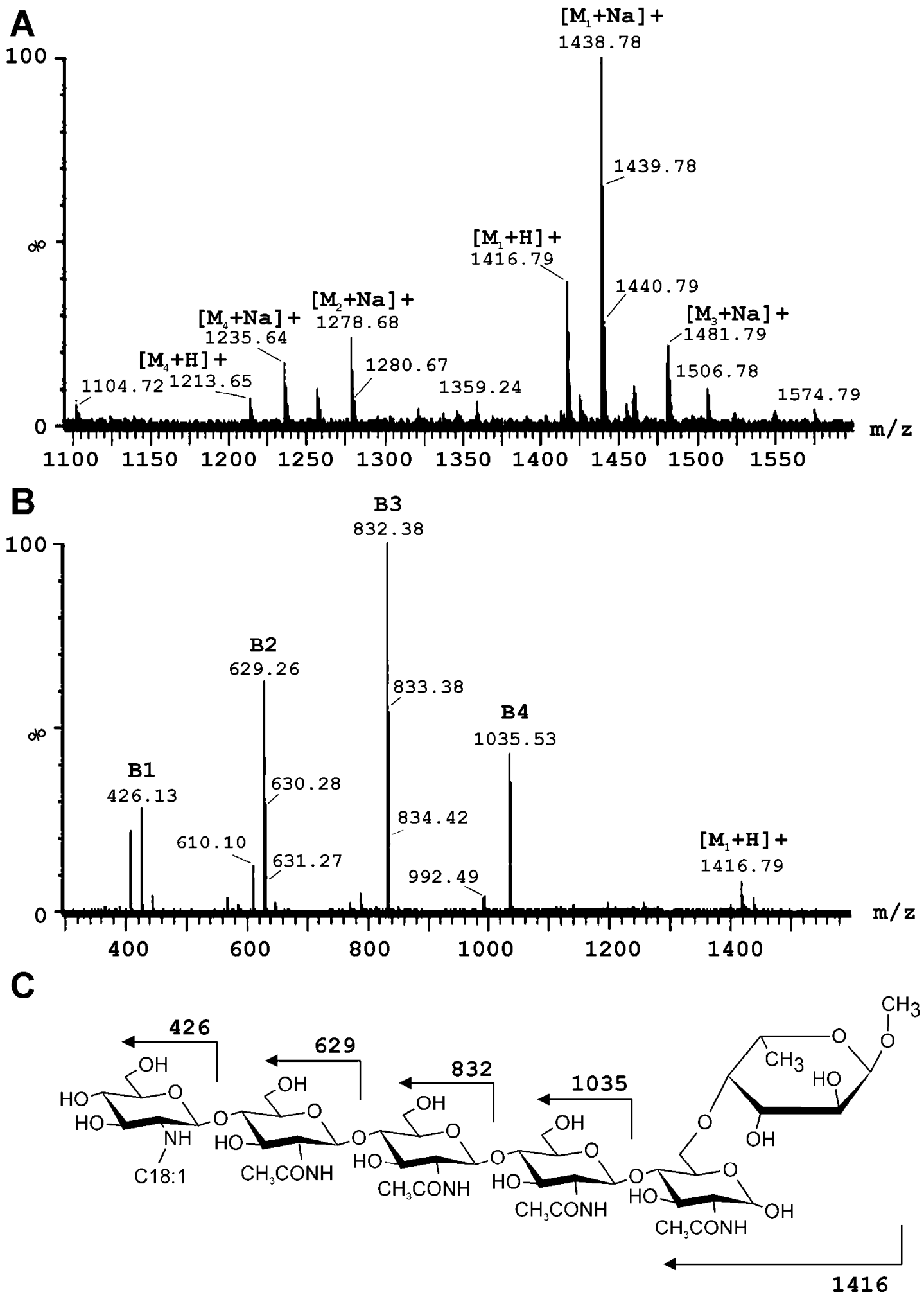

Fig. 3. Mass spectrometric analysis of the $\mathrm{C} 18$ reverse-phase fraction induced by the flavonoid naringenin. A, Electrospray ionization mass spectrometry spectrum of the $\mathrm{C} 18$ reverse-phase fraction that is induced by naringenin. B, Tandem mass spectrometry spectrum of the major nodulation (Nod) factor present in the reverse-phase fraction. C, Structure and expected B fragmentation pattern of the major Nod factor of Bradyrhizobium sp. strain ORS285. 


\section{B. japonicum USDA110 forms stem and root nodules on the tropical aquatic legume $A$. afraspera.}

Photosynthetic Bradyrhizobium sp. strain ORS285 forms nod gene-dependent nodules on both the roots and stems of $A$. afraspera plants. Because the major LCO synthesized by $\mathrm{Bra}$ dyrhizobium sp. strain ORS285, Nod-V(C18:1, MeFuc), is exactly the same as the major LCO synthesized by B. japonicum USDA110 (Sanjuan et al. 1992), we wondered whether the nonphotosynthetic $B$. japonicum USDA110 is able to stem and root nodulate $A$. afraspera. B. japonicum USDA110 NF are induced by the isoflavones genistein and daidzein (Kosslak et al. 1987) whereas isoflavones do not induce nod gene expression in Bradyrhizobium sp. strain ORS285 (Table 1). HPLC and spectral analysis of the root exudate of $A$. afraspera plants showed that, in addition to "naringenin-like" flavonoids, the isoflavone daidzein was a major compound in the root exudate (data not shown). This indicates that the synthesis of NF by $B$. japonicum USDA110 is likely induced upon contact with $A$. afraspera plants. To analyze whether this leads to the formation of nodules, we inoculated the stems and roots of 1-weekold $A$. afraspera seedlings with B. japonicum USDA110 and compared this with the nodule formation by Bradyrhizobium sp. strain ORS285. Two weeks after inoculation, the number of nodules formed on the root of $A$. afraspera plants infected with $B$. japonicum USDA110 was slightly higher compared with plants infected with Bradyrhizobium sp. strain ORS285 (Fig. 4A). In contrast, the number of nodules on the stems of A. afraspera plants infected with B. japonicum USDA110 was approximately two- to threefold lower compared with plants infected with Bradyrhizobium sp. strain ORS285 (Fig. 4A). For stem nodules containing B. japonicum USDA110, the nitrogenase enzyme activity per nodule as measured via the ARA was lower compared with nodules containing Bradyrhizobium sp. strain ORS285 (Fig. 4B) Macroscopic analysis of both stems and roots inoculated by $B$. japonicum USDA110 showed that the formed nodules have a similar size and shape compared with stem and root nodules produced by Bradyrhizobium sp. strain ORS285 (Fig. 5). Moreover, as with Bradyrhizobium sp. strain ORS285, root nodules induced by $B$. japonicum USDA110 are found only at the base of lateral roots. Taken together, these results indicate that B. japonicum USDA110 is able to form nodules on the tropical aquatic legume $A$. afraspera but that the nitrogenase activity per stem nodule is less compared with stem nodules formed by the original symbiotic partner, Bradyrhizobium sp. strain ORS285. However, because $A$. afraspera plants infected with B. japonicum USDA110 do not show any signs of nitrogen limitation, the amount of $\mathrm{N}_{2}$ fixation by the stem nodules seem to be sufficient to stimulate the growth of the plant.

\section{DISCUSSION}

Aeschynomene spp. that form nodules on both the roots and stems are, in general, found to be nodulated by photosynthetic Bradyrhizobium spp. In contrast to many other rhizobia-leg-
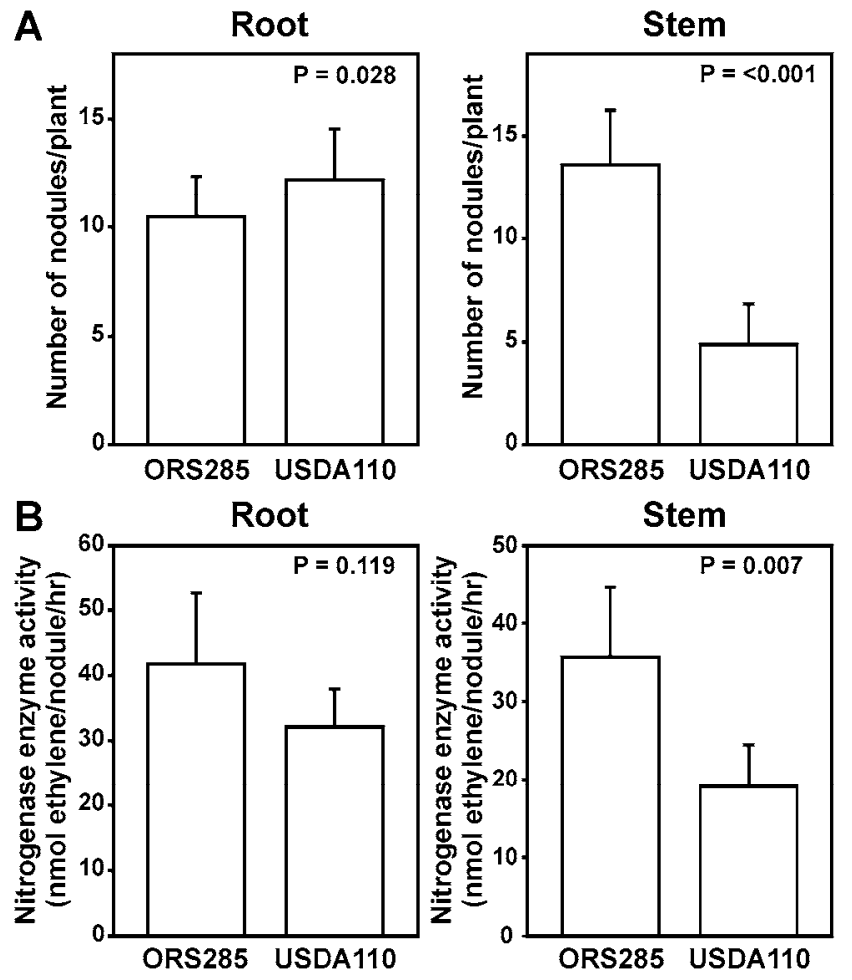

Fig. 4. Bradyrhizobium japonicum USDA110 nodulates the root and stem of the tropical aquatic legume Aeschynomene afraspera. A, Roots or stems from A. afraspera were inoculated with Bradyrhizobium sp. strain ORS285 and $B$. japonicum USDA 110 , respectively, and the number of nodules was determined 15 days postinfection. B, A. afraspera roots or stems were inoculated with Bradyrhizobium sp. strain ORS285 and B. japonicum USDA 110, respectively, and the nitrogenase enzyme activity per nodule was determined by the acetylene reduction assay. The amount of nodules and nitrogenase activity is the average of 10 infected plants. The $P$ value of Student's $t$ test on the experimental data is given in the upper right hand corner of the bar diagrams.

Table 3. Bradyrhizobium sp. strain ORS285 genes encoding enzymes and regulators involved in the synthesis of nodulation (Nod) factors ${ }^{\mathrm{a}}$

\begin{tabular}{|c|c|c|c|}
\hline Gene & Enzyme, transporter, regulator & Accession number & Reference \\
\hline \multicolumn{4}{|l|}{ Enzyme } \\
\hline $\operatorname{nod} \mathrm{A}$ & $\mathrm{N}$-acyltransferase & AAK50870.1 & Chaintreuil et al. (2001) \\
\hline $\operatorname{nodB}$ & Chitooligosaccharide deacetylase & AAK50871.1 & Chaintreuil et al. (2001) \\
\hline nodC & $\mathrm{N}$-acetylglucosaminyl transferase & AAK50872.1 & Chaintreuil et al. (2001) \\
\hline nodS & $\mathrm{N}$-methyl transferase & FQ790398 & This study \\
\hline $\operatorname{nod} \mathrm{U}$ & 6-O-carbamoyl transferase & FQ790399 & This study \\
\hline $\operatorname{nod} \mathrm{Z}$ & $\alpha-1,6$-Fucose transferase & FQ790403 & This study \\
\hline noeI & 2- $O$-methyltransferase (fragment) & FQ790402 & This study \\
\hline nolL & 4- $O$-acetyl transferase & AAK50867.1 & Chaintreuil et al. (2001) \\
\hline \multicolumn{4}{|c|}{ Transporter } \\
\hline nodI & ABC transporter, ATPase domain & FQ790400 & This study \\
\hline nodJ & $\mathrm{ABC}$ transporter, membrane domain & FQ790401 & This study \\
\hline \multicolumn{4}{|l|}{ Regulator } \\
\hline nod D1 & Transcriptional regulator NodD1 & FQ790406 & This study \\
\hline nod D2 & Transcriptional regulator NodD2 & FQ790405 & This study \\
\hline nolA & Transcriptional regulator NolA & FQ790397 & This study \\
\hline
\end{tabular}

${ }^{a}$ Common (bold) and specific genes encoding enzymes, transporters, and regulators involved in the synthesis and secretion of Nod factors as found in published and unpublished DNA sequences of Bradyrhizobium sp. strain ORS285. 
ume interactions, relatively little is known about the symbiotic signal molecules involved in the molecular dialogue between photosynthetic Bradyrhizobium spp. and Aeschynomene plants. In this study, we analyzed the nod gene expression of photosynthetic Bradyrhizobium sp. strain ORS285 and the signal molecules that are synthesized upon their induction.

Plant roots secrete a lot of molecules into the rhizosphere, of which flavonoids have been shown to be strong inducers of nod gene expression in many rhizobia. Growth of a nodB-lacZ reporter strain in the presence of different flavonoids showed that the flavanones liquiritegenin and naringenin result in the highest induction of $\beta$-galactosidase activity (Table 1 ). Spectral and mass spectrometric analysis of the root exudate of $A$. afraspera - a species that is nodulated by Bradyrhizobium sp. strain ORS285 in a nod gene-dependent manner-showed the presence of many "naringenin"-like flavonoids and the isoflavonoid daidzein (A. Renier, unpublished results). The latter flavonoid did not induce nod gene expression in vitro; therefore, flavanones of the naringenin type are likely the natural inducers of Bradyrhizobium sp. strain ORS285 nod gene expression when interacting with $A$. afraspera in the rhizosphere.

Nodulation genes can be classified into two categories: the common nod genes (nodABC) that are involved in the formation of the $N$-acylated chitin oligomer NF core and specific nod genes (nod $\mathrm{Z}, \operatorname{nod} \mathrm{H}, \operatorname{nod} \mathrm{S}$, and so on) that encode enzymes involved in the synthesis and transfer of additional modifying groups on the NF core. Analysis of published (Chaintreuil et al. 2001) and unpublished DNA sequences showed that Bradyrhizobium sp. strain ORS285 contains the common nodABC genes involved in the synthesis of the NF core and the specific nodSUZ, noeI, and nolL genes involved in $N$-methylation (nodS) (Geelen et al. 1995), and carbamoylation (nodU) (Jabbouri et al. 1995), fucosylation (nodZ) (Stacey et al. 1994) of the NF core structure and methylation (noeI) (Jabbouri et al. 1998 ) or 4-O-acetylation of the fucosyl residue (nolL) (Berck et al. 1999). Except for $\mathrm{N}$-methylation and 4- $O$-acetylation, $\mathrm{NF}$ with all other above-mentioned modifications have been found in the culture supernatant isolated from Bradyrhizobium sp. strain ORS285 cells grown in the presence of naringenin (Table 2). This indicates that the genes encoding for enzymes involved in these modifications are expressed in the presence of naringenin but, in addition, that Bradyrhizobium sp. strain ORS285 might be capable of synthesizing even a larger collection of NF.

Despite the low amino acid identities of Nod proteins from Bradyrhizobium sp. strain ORS285 and B. japonicum strains such as USDA110, the chemical structure of the major LCO synthesized by Bradyrhizobium sp. strain ORS285 (V, C18:1, MeFuc) is exactly the same as the major LCO synthesized by $B$. japonicum strains (Carlson et al. 1993; Sanjuan et al. 1992). The important sequence divergence from other Nod proteins as found for Bradyrhizobium sp. strain ORS285 seems to be a general characteristic of photosynthetic stem-nodulating Bradyrhizobium spp. that are capable of nodulating Aeschynomene spp. in a nod gene-dependent and nod gene-independent manner (Miche et al. 2010). It has been suggested that, for these photosynthethic Bradyrhizobium spp., the nod gene-dependent association with host plants is an alternative ecological lifestyle and that a relaxation of selection pressure for this lifestyle has resulted in an important sequence divergence of Nod proteins (Miche et al. 2010). In Bradyrhizobium sp. strain ORS285, this divergence has led to the synthesis of NF being induced by flavanones, flavones, and flavonoles whereas, in B. japonicum strains, these are induced by isoflavones (genistein and daidzein) (Kosslak et al. 1987). Moreover, B. japonicum strains contain a two-component flavonoid recognition system (NodV/W) that positively regulates nod gene expression and that is absent in
Bradyrhizobium sp. strain ORS285. Thus, except for a different induction of nod gene expression in photosynthetic Bradyrhizobium sp. strain ORS285, the rest of the molecular dialogue between plant and bacteria might be similar to that of nonphotosynthetic B. japonicum strains. Indeed, B. japonicum USDA110 was able to form nodules on both the root and stem of $A$. afraspera (Figs. 4 and 5). In contrast to root nodules, the number and nitrogenase enzyme activity of stem nodules induced by B. japonicum USDA110 was less compared with Bradyrhizobium sp. strain ORS285 (Fig. 4B and D). However, this is likely due to the nonphotosynthetic characteristic of B. japonicum USDA110 because, for photosynthetic Bradyrhizobium spp., it has been shown that the ability to photosynthesize contributes to the efficiency to form nodules on the stem (Giraud et al. 2000) and provides energy for nitrogenase activity inside stem nodules (Evans et al. 1990). Interestingly, B. japonicum USDA110 forms nodules at the base of lateral roots and on the stem of $A$. afraspera, whereas it does not form these types of nodules on its original host plants, such as soybean and sirato. This indicates that the ability to stem nodulate and to form nodules at the base of lateral roots is primary determined by the plant and not by the bacterium.

Taken together, here we have shown that the nod gene-dependent molecular dialogue between photosynthetic Bradyrhizobium sp. strain ORS285 and tropical aquatic legumes of the Aeschynomene genus is similar to the classic rhizobiumlegume interaction (i.e., induction by host plant flavonoids and subsequent synthesis of LCO). However, Bradyrhizobium sp. strain ORS285 is also able to establish a symbiotic interaction with certain species of the Aeschynomene genus in a nod gene-independent manner. Therefore, future studies should address whether, during the interaction with these "nod-independent" Aeschynomene spp., the bacterial nod genes are expressed, whether NF-like molecules are synthesized, and whether regulators known to play a role in nod gene-dependent symbiosis (NodD) are important. These stud-

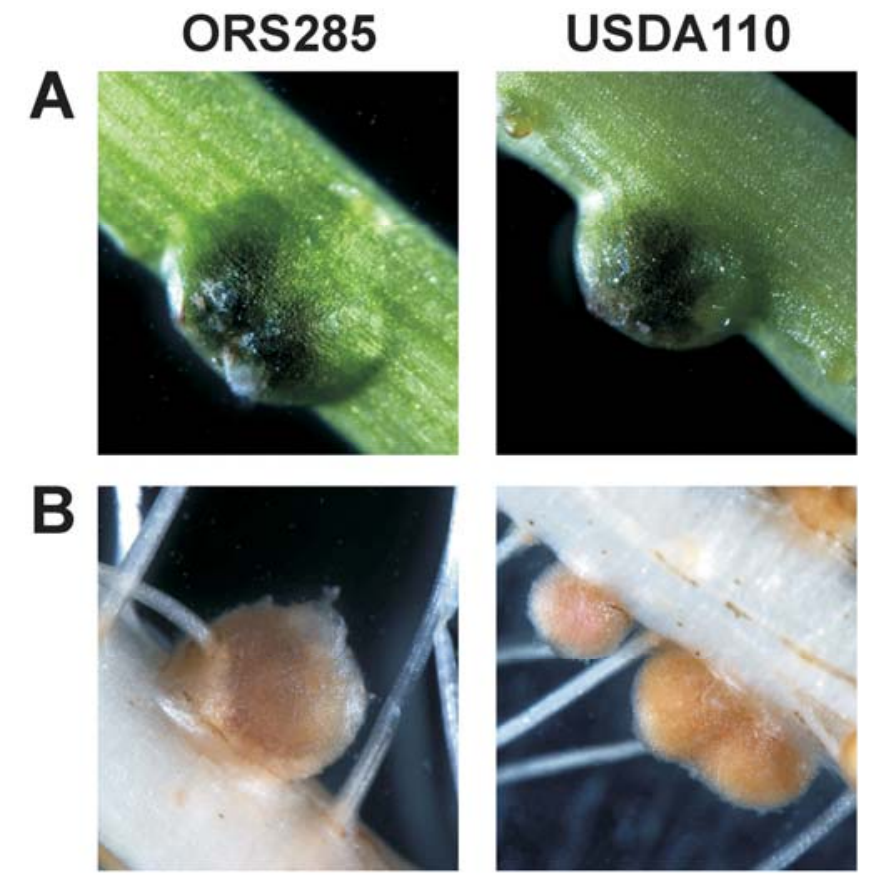

Fig. 5. Nodules induced on Aeschynomene afraspera by Bradyrhizobium sp. strain ORS285 and Bradyrhizobium japonicum USDA110 have the same morphology. A, Stem nodules and B, root nodules of A. afraspera 17 days postinfection formed by Bradyrhizobium sp. strain ORS285 and B. japonicum USDA110. 
ies will enhance our understanding of the symbiosis between photosynthetic Bradyrhizobium and Aeschynomene spp. and, in general, may shine a light on how the symbiosis between rhizobia and legumes has evolved.

\section{MATERIALS AND METHODS}

\section{Bacterial strains and growth conditions.}

Bradyrhizobium sp. strain ORS285 (Molouba et al. 1999), its derivative Bradyrhizobium sp. strain ORS285::nodB-lacZkan (Giraud et al. 2007), and Bradyrhizobium japonicum USDA110 (gift of M. J. Sadowsky, University of Minnesota, Minneapolis, MN, U.S.A.) were grown in modified YM medium (Giraud et al. 2000) or a minimal growth medium (buffered nodulation medium [BNM-B]; $\mathrm{pH}$ 6.8) at $37^{\circ} \mathrm{C}$. BNM-B is a synthetic plant growth medium (Ehrhardt et al. 1992) that has been supplemented with succinate $(10 \mathrm{mM})$, glutamate $(6 \mathrm{mM})$, and a cocktail of vitamins (riboflavin at $0.2 \mu \mathrm{g} / \mathrm{ml}$, biotin at $0.12 \mu \mathrm{g} / \mathrm{ml}$, thiamine- $\mathrm{HCl}$ at $0.8 \mu \mathrm{g} / \mathrm{ml}$, myo-inositol at $0.5 \mu \mathrm{g} / \mathrm{ml}$, p-aminobenzoic acid at $0.1 \mu \mathrm{g} / \mathrm{ml}$, nicotinic acid at $0.5 \mu \mathrm{g} / \mathrm{ml}$, calcium pantohenate at $0.8 \mu \mathrm{g} / \mathrm{ml}$, and cyanocobalamin at $1 \mathrm{ng} / \mathrm{ml}$ ) to support growth of Bradyrhizobium strains.

\section{Plant growth.}

Seed of Aeschynomene afraspera was surface sterilized in concentrated sulfuric acid for $45 \mathrm{~min}$. After five washes with $50 \mathrm{ml}$ of sterile water, the seed was incubated overnight in sterile water at room temperature. After one wash with sterile water, the seed was spread on $1 \%$ water agar plates and germinated upside down overnight at $37^{\circ} \mathrm{C}$ in the dark. The germinated seedlings were transferred to sterile Falcon tubes that had been closed by a sterile aluminum cover and which contained $55 \mathrm{ml}$ of nitrogen-free BNM medium (Ehrhardt et al. 1992). To allow passage of the radicle, a small hole in the aluminum cover was made using a sterile toothpick. To protect the roots from light exposure, the body of the Falcon tube was covered with aluminum foil. The Falcon tubes containing the seedlings were placed in a small greenhouse and grown in a growth chamber with a 16-h light regime and $70 \%$ humidity at $28^{\circ} \mathrm{C}$. To obtain a high humidity inside the small greenhouse, it contained 1 liter of sterile water. After 1 week of growth, the roots were inoculated with $0.5 \mathrm{ml}$ of Bradyrhizobium sp. strain ORS285 or B. japonicum USDA110 cells with an optical density at $600 \mathrm{~nm}\left(\mathrm{OD}_{600}\right)$ of 1.0 and the growth of the plants was continued for 2 to 3 weeks. Stem nodulation was performed by careful "painting" of the stem using a Buccal swab that had been soaked in a bacterial culture with an OD of 1.0.

\section{Nodule number and nitrogenase activity in nodules.}

Two weeks after inoculation, the number of nodules on the roots and stems were counted and, after 17 days, the acetylene reduction assay (ARA) was used to measure the nitrogenase enzyme activity. The ARA is a very sensitive assay to quantify the relative nitrogenase enzyme activity in $\mathrm{N}_{2}$-fixing samples. For each experimental condition, 10 plants were used and the experiments were repeated at least two times. For this, one plant was placed into a $150-\mathrm{ml}$ glass bottle containing $1 \mathrm{ml}$ of water and closed with a screw cap containing an airtight rubber septum. Air in the glass bottle was replaced with $10 \% \mathrm{CH}_{4}$ in air, following by overnight incubation at $28^{\circ} \mathrm{C}$ in the dark. After incubation, 1-ml gas samples from the bottles were sampled, and the ethylene concentration was assayed using a gas chromatograph (Agilent 6850 series GC system; Agilent Technologies, Santa Clara, CA, U.S.A.). Operating conditions for the gas chromatograph were as follows: column, Inventory $\mathrm{AB} 001(50 \mathrm{~m}$ by $530 \mu \mathrm{M}$ by $15 \mu \mathrm{M})$; nitrogen as carrier gas at a flow rate of $12.8 \mathrm{ml} / \mathrm{min}$; temperatures: column, $60^{\circ} \mathrm{C}$; injector port, $120^{\circ} \mathrm{C}$; flame ionization detector, $250^{\circ} \mathrm{C}$.

nodB gene inducing capabilities of flavonoids.

The Bradyrhizobium sp. strain ORS285 nodB-lacZ reporter strain was used to asses the capacities of flavonoids to induce the expression of the nodB-lacZ transcriptional fusion. Purified flavonoids were purchased from Extrasynthese (Genay, France) or Sigma-Aldrich (St. Louis). Bradyrhizobium sp. strain ORS285::nodB-lacZ was grown in BNM-B medium until an $\mathrm{OD}_{600}$ of approximately 0.4 . Subsequently, the bacterial culture was diluted into fresh BNM-B medium $\left(\mathrm{OD}_{600}=0.1\right)$ and supplemented with flavonoid. To be able to detect the induction of NodB expression by less-efficient flavonoids, a relatively high flavonoid concentration was used in the assay (20 $\mu \mathrm{M}$ final concentration). After $24 \mathrm{~h}$ of growth at $28^{\circ} \mathrm{C}, \beta$-galactosidase activities were measured according to the method of Miller (Miller 1972).

\section{NF extraction and purification.}

Bradyrhizobium sp. strain ORS285 was grown in modified YM medium until the culture reached an absorbance at 600 $\mathrm{nm}$ of 0.05 . Then, the cells were induced to produce NF by the addition of naringenin $(20 \mu \mathrm{M}$ final concentration) and grown for $72 \mathrm{~h}$ at $37^{\circ} \mathrm{C}$. NF were extracted from the filtered culture supernatant by partition with $n$-butanol as described by Roche and associates (1991). Purification of different NF was performed on a high-performance liquid chromatography (HPLC) system (Waters 2690 separation module; Waters, Milford, MA, U.S.A.) equipped with a semipreparative $\mathrm{C}_{18}$ reverse-phase column ( $5 \mu \mathrm{m}, 46$ by $200 \mathrm{~mm}$; Equisorb ODS2 CIL-Cluzeau) using an isocratic gradient of solvent A (water-acetonitrile, $80: 20$ [vol/vol]) for $10 \mathrm{~min}$, followed by a 20-min linear gradient from solvent A to solvent B (100\% acetonitrile), and finally an isocratic gradient of solvent B for $10 \mathrm{~min}$, at a flow rate of 1 $\mathrm{ml} \mathrm{min}^{-1}$. The eluent of the HPLC column was monitored at $206 \mathrm{~nm}$. Acetonitrile present in the collected fractions was removed by two successive freeze-drying steps.

\section{Mass spectrometry.}

HPLC fractions containing putative lipochitooligosaccarides (LCO) were analyzed using an ESI-QqToF Ultima apparatus (Waters) by direct injection. Spectra were recorded in both the positive and the negative mode and peaks detected in the expected range $(\mathrm{m} / \mathrm{z} 1,000$ to 1,500 for the simple-charged species or 600 to 700 for the double-charged ones) were submitted to tandem mass spectrometry (MS/MS) to confirm their LCO nature.

Energies were the following: probe, $3 \mathrm{kV}$; cone, $100 \mathrm{~V}$; Rf, $70 \mathrm{~V}$; collision cell, $15 \mathrm{~V}$ for MS and $30 \mathrm{~V}$ for MS/MS. collision gas, argon. Direct inlet: solvent, $\mathrm{AcCN} / \mathrm{H}_{2} \mathrm{O}$ 1:1, $1 \%$ acetic acid; rate, $10 \mu \mathrm{l} \mathrm{min}^{-1}$. Concentrations were approximately $10^{-4} \mathrm{M}$.

\section{Genome sequencing and construction of a genomic draft of Bradyrhizobium sp. strain ORS285.}

Genomic DNA from Bradyrhizobium sp. strain ORS285 was isolated from a 5-day-old culture grown in modified YM medium at $37^{\circ} \mathrm{C}$. Genomic DNA was sequenced by the Genoscope using the pyrosequencing technology developed by Roche (Basel, Switzerland). In total, 943,814 GSflx reads, corresponding to 26-fold coverage, were assembled with Newbler (version 1.1.03.24). Contigs of more than 500 nucleotides (301; total size 7.6 Mb) were integrated into the Microscope Platform and manually annotated. DNA sequences of genes of Bradyrhizobium sp. strain ORS285 discussed in this article are deposited in GenBank (Table 3 lists accession numbers). 


\section{ACKNOWLEDGMENTS}

This work was supported by grants from the French national research agency (ANR-NEWNOD-2006-BLAN-0095 and ANR-SESAM-2010BLAN-170801).

\section{LITERATURE CITED}

Alazard, D. 1985. Stem and root nodulation in Aeschynomene spp. Appl. Environ. Microbiol. 50:732-734.

Alazard, D. 1990. Nitrogen fixation in pure culture by rhizobia isolated from stem nodules of tropical Aeschynomene species. FEMS (Fed. Eur. Microbiol. Soc.) Lett. 68:177-182.

Bec-Ferte, M. P., Krishnan, H. B., Savagnac, A., Pueppke, S. G., and Prome, J. C. 1996. Rhizobium fredii synthesizes an array of lipooligosaccharides, including a novel compound with glucose inserted into the backbone of the molecule. FEBS (Fed. Eur. Biochem. Soc.) Lett. 393:273-279.

Berck, S., Perret, X., Quesada-Vincens, D., Prome, J., Broughton, W. J., and Jabbouri, S. 1999. NolL of Rhizobium sp. strain NGR234 is required for $O$-acetyltransferase activity. J. Bacteriol. 181:957-964.

Caetano-Anolles, G., Crist-Estes, D. K., and Bauer, W. D. 1988. Chemotaxis of Rhizobium meliloti to the plant flavone luteolin requires functional nodulation genes. J. Bacteriol. 170:3164-3169.

Carlson, R. W., Sanjuan, J., Bhat, U. R., Glushka, J., Spaink, H. P., Wijfjes, A. H., van Brussel, A. A., Stokkermans, T. J., Peters, N. K., and Stacey, G. 1993. The structures and biological activities of the lipooligosaccharide nodulation signals produced by type I and II strains of Bradyrhizobium japonicum. J. Biol. Chem. 268:18372-18381.

Chaintreuil, C., Boivin, C., Dreyfus, B., and Giraud, E. 2001. Characterization of the common nodulation genes of the photosynthetic Bradyrhizobium sp. ORS285 reveals the presence of a new insertion sequence upstream of nodA. FEMS (Fed. Eur. Microbiol. Soc.) Microbiol. Lett. 194:83-86.

Denarie, J., Debelle, F., and Prome, J. C. 1996. Rhizobium lipo-chitooligosaccharide nodulation factors: Signaling molecules mediating recognition and morphogenesis. Annu. Rev. Biochem. 65:503-535.

D'Haeze, W., and Holsters, M. 2002. Nod factor structures, responses, and perception during initiation of nodule development. Glycobiology 12:79-105.

Dharmatilake, A. J., and Bauer, W. D. 1992. Chemotaxis of Rhizobium meliloti towards nodulation gene-inducing compounds from Alfalfa roots. Appl. Environ. Microbiol. 58:1153-1158.

Ehrhardt, D. W., Atkinson, E. M., and Long, S. R. 1992. Depolarization of Alfalfa root hair membrane potential by Rhizobium meliloti Nod factors. Science 256:998-1000.

Evans, W. R., Fleischman, D. E., Calvert, H. E., Pyati, P. V., Alter, G. M., and Rao, N. S. 1990. Bacteriochlorophyll and photosynthetic reaction centers in Rhizobium strain BTAi 1. Appl. Environ. Microbiol. 56:34453449.

Geelen, D., Leyman, B., Mergaert, P., Klarskov, K., Van, M. M., Geremia, R., and Holsters, M. 1995. NodS is an S-adenosyl-L-methioninedependent methyltransferase that methylates chitooligosaccharides deacetylated at the non-reducing end. Mol. Microbiol. 17:387-397.

Giraud, E., and Fleischman, D. 2004. Nitrogen-fixing symbiosis between photosynthetic bacteria and legumes. Photosynth. Res. 82:115-130.

Giraud, E., Hannibal, L., Fardoux, J., Vermeglio, A., and Dreyfus, B. 2000. Effect of Bradyrhizobium photosynthesis on stem nodulation of Aes- chynomene sensitiva. Proc. Natl. Acad. Sci. U.S.A. 97:14795-14800.

Giraud, E., Moulin, L., Vallenet, D., Barbe, V., Cytryn, E., Avarre, J. C., Jaubert, M., Simon, D., Cartieaux, F., Prin, Y., Bena, G., Hannibal, L., Fardoux, J., Kojadinovic, M., Vuillet, L., Lajus, A., Cruveiller, S., Rouy, Z., Mangenot, S., Segurens, B., Dossat, C. , Franck, W.L., Chang, W.S., Saunders, E., Bruce, D. and Richardson, P. and Normand, P., Dreyfus, B., Pignol, D., Stacey, G., Emerich, D., Vermeglio, A., Medigue, C. and Sadowsky, M. 2007. Legumes symbioses: Absence of nod genes in photosynthetic bradyrhizobia. Science 316:1307-1312.

Jabbouri, S., Fellay, R., Talmont, F., Kamalaprija, P., Burger, U., Relic, B., Prome, J. C., and Broughton, W. J. 1995. Involvement of nodS in Nmethylation and nodU in 6-O-carbamoylation of Rhizobium sp. NGR234 nod factors. J. Biol. Chem. 270:22968-22973.

Jabbouri, S., Relic, B., Hanin, M., Kamalaprija, P., Burger, U., Prome, D., Prome, J. C., and Broughton, W. J. 1998. NolO and noeI (HsnIII) of Rhizobium sp. NGR234 are involved in 3-O-carbamoylation and 2-Omethylation of Nod factors. J. Biol. Chem. 273:12047-12055.

Kosslak, R. M., Bookland, R., Barkei, J., Paaren, H. E., and Appelbaum, E. R. 1987. Induction of Bradyrhizobium japonicum common nod genes by isoflavones isolated from Glycine max. Proc. Natl. Acad. Sci. U.S.A. 84:7428-7432.

Miche, L., Moulin, L., Chaintreuil, C., Contreras-Jimenez, J. L., MuniveHernandez, J. A., del Carmen Villegas-Hernandez, M., Crozier, F., and Bena, G. 2010. Diversity analyses of Aeschynomene symbionts in tropical Africa and Central America reveal that nod-independent stem nodulation is not restricted to photosynthetic bradyrhizobia. Environ. Microbiol. 12:2152-2164.

Miller, J. H. 1972. Experiments in Molecular Genetics. Cold Spring Harbor Laboratory Press, Cold Spring Harbor, NY, U.S.A.

Molouba, F., Lorquin, J., Willems, A., Hoste, B., Giraud, E., Dreyfus, B., Gillis, M., de Lajudie, P., and Masson-Boivin, C. 1999. Photosynthetic bradyrhizobia from Aeschynomene spp. are specific to stem-nodulated species and form a separate 16S ribosomal DNA restriction fragment length polymorphism group. Appl. Environ. Microbiol. 65:3084-3094.

Perret, X., Staehelin, C., and Broughton, W. J. 2000. Molecular basis of symbiotic promiscuity. Microbiol. Mol. Biol. Rev. 64:180-201.

Poupot, R., Martinez-Romero, E., and Prome, J. C. 1993. Nodulation factors from Rhizobium tropici are sulfated or nonsulfated chitopentasaccharides containing an $\mathrm{N}$-methyl-N-acylglucosaminyl terminus. Biochemistry 32:10430-10435.

Price, N. P., Relic, B., Talmont, F., Lewin, A., Prome, D., Pueppke, S. G., Maillet, F., Dénarié, J., Promé, J. C., and Broughton, W. J. 1992. Broadhost-range Rhizobium species strain NGR234 secretes a family of carbamoylated, and fucosylated, nodulation signals that are $O$-acetylated or sulphated. Mol. Microbiol. 6:3575-3584.

Sanjuan, J., Carlson, R. W., Spaink, H. P., Bhat, U. R., Barbour, W. M., Glushka, J., and Stacey, G. 1992. A 2-O-methylfucose moiety is present in the lipo-oligosaccharide nodulation signal of Bradyrhizobium japonicum. Proc. Natl. Acad. Sci. U.S.A. 89:8789-8793.

Spaink, H. P. 1992. Rhizobial lipo-oligosaccharides: Answers and questions. Plant Mol. Biol. 20:977-986.

Sprent, J. I. 2008. Legume Nodulation: A Global Perspective. Wiley Blackwell, New York.

Stacey, G., Luka, S., Sanjuan, J., Banfalvi, Z., Nieuwkoop, A. J., Chun, J. Y., Forsberg, L. S., and Carlson, R. 1994. NodZ, a unique host-specific nodulation gene, is involved in the fucosylation of the lipooligosaccharide nodulation signal of Bradyrhizobium japonicum. J. Bacteriol. 176:620-633. 